\title{
BMJ Open Quality of life of older adults and associated factors in Ghanaian urban slums: a cross-sectional study
}

\author{
Priscilla Yeye Adumoah Attafuah (D) , ${ }^{1,2}$ Irma Everink, ${ }^{2}$ Aaron Asibi Abuosi (i) , ${ }^{3}$ \\ Christa Lohrmann, ${ }^{4}$ Jos M G A Schols ${ }^{2,5}$
}

To cite: Attafuah PYA, Everink I, Abuosi AA, et al. Quality of life of older adults and associated factors in Ghanaian urban slums: a crosssectional study. BMJ Open 2022;12:e057264. doi:10.1136/ bmjopen-2021-057264

- Prepublication history and additional supplemental material for this paper are available online. To view these files, please visit the journal online (http://dx.doi.org/10.1136/ bmjopen-2021-057264).

Received 11 September 2021 Accepted 20 January 2022

D) Check for updates

(C) Author(s) (or their employer(s)) 2022. Re-use permitted under CC BY-NC. No commercial re-use. See rights and permissions. Published by BMJ.

For numbered affiliations see end of article.

Correspondence to Dr Priscilla Yeye Adumoah Attafuah;

pyaattafuah@ug.edu.gh

\section{ABSTRACT}

Objective This study provides insight into the quality of life (QoL) of older adults living in urban slums in Ghana.

Design The study employed a community-based, crosssectional design to assess QoL among older adults in two slums between April and May 2020. QoL was assessed using the WHO Quality of Life-Brief version (WHOQOLBREF) questionnaire.

Settings Participants were drawn from two slums in Ghana, one in a fishing-dominated community and the other in an industrial community.

Participants This study included 400 participants aged 60 and above who had lived in either slum for at least 1 month and were able to communicate verbally. Results Although the means of all participants' transformed scores were poor in the physical and psychological domains, they were moderate in all other domains. When viewed as a whole, the perceived overall QoL is neither poor nor good and participants were neither satisfied nor dissatisfied with their health. Participants had a moderate level of QoL in the WHOQOL-BREF psychological (mean score 45.7), social (mean score 57.0) and environmental (mean score 51.6) domains. The mean score for physical QoL of older adults was 43.3, which denotes poor QoL. In all domains, male participants have a significantly higher mean $\mathrm{Q} \mathrm{L}$ than their female counterparts. An analysis of variance comparing the living arrangements of participants showed that those who lived with extended family had high mean scores in environmental QoL, overall QoL and satisfaction with health. Regression analysis revealed that $\mathrm{QoL}$ was influenced mostly by the environmental (46.2\%), followed by the psychological (43.7\%), physical (31\%) and social (20.4\%) domains.

Conclusions The findings from this study show that older adults living in slums had moderate psychological, social and environmental QoL and poor physical QoL. Although the mean scores for QoL are higher than anticipated, health policy development must take into account the specific needs of older adults.

\section{INTRODUCTION}

The difference in life expectancy of people in developed countries and people living in African countries is approximately 10 years. ${ }^{1}$ These differences are due to a variety of factors, including demographic differences,

\section{Strengths and limitations of this study}

- This is the first study to assess the quality of life of older adults in two different slum communities in Ghana.

- There was a $100 \%$ response rate and there were no missing data, which contribute to the methodological strength of the study.

- The $100 \%$ response rate can be attributed to the fact that all participants were approached personally and the presence of the first author and research assistants which encouraged respondents.

- The findings of this study can assist in policy development to include strategies to further improve the quality of life of older adults in slums.

- Most slum dwellers were in anticipation of financial gifts after participating but this was not possible and breakfast packages were given. This disappointment could have dettered others who qualified from participating and could have been a limitation.

- Another limitation could be ascribed to the crowded nature of the slum setting: there was no privacy during data collection and other slum dwellers were often listening to the interviews, which could have influenced the answers given by the participants.

varying family and social structures, social security arrangements, health infrastructure, and spiritual beliefs. ${ }^{2-4}$ These factors impact how a person addresses health issues and other aspects of their life. Life expectancy in Africa is rising, in line with global trends and despite regional differences. However, an increased life expectancy does not always imply an improved quality of life (QoL). Ageing often comes with problems affecting the QoL, such as loneliness, ill health and depression. ${ }^{5-7}$ As a result, as people in African societies are ageing, the QoL of older adults in African countries is increasingly becoming an important issue. ${ }^{89}$

QoL is defined by the WHO as 'an individual's perception of their position in life in the context of the culture and value systems in which they live and with their goals, 
expectations, standards and concerns'.$^{10}$ Older adults are particularly vulnerable to poor QoL as a result of changes and events in their physical health, psychological state, social circumstances and relationship to their environment. ${ }^{811} 12$ Ageing may decrease human vitality, which leads to frail health and dependency. Moreover, frailty may express itself as cognitive impairment and neglect in the psychological and social domains, respectively. When this is combined with deplorable living conditions, the QoL of these older adults can be affected.

Slums are a visible evidence of deplorable living conditions. Slums often lack basic amenities, are overcrowded and are polluted. ${ }^{13} 14$ In developing countries, mainly African countries, rural-urban migration is one of the factors that result in slum communities. ${ }^{13-17}$ Slum-dwelling older adults are predisposed to non-communicable diseases as they age. They are also susceptible to different forms of communicable diseases due to unsanitary conditions and lack of access to healthcare. ${ }^{14151819}$ As a result, the overall health status of older adults in slums has been reported to be lower than that of older adults living in formal settlements. ${ }^{20-22}$

Supporting older people in slums is an important objective of the WHO 'Global strategy and action plan on ageing and health 2016-2030'. ${ }^{23}$ One of the targets of the Millennium Development Goals 7 was to achieve a significant improvement in the lives of at least 100 million slum dwellers worldwide by 2020 . However, there have not been any marked improvements in Ghanaian slums as of yet. ${ }^{2425}$

Many studies have been conducted globally on the QoL of older adults either in the community or in care homes ${ }^{26}{ }^{27}$ and also in those with different health conditions. ${ }^{28-30}$ However, there is a dearth of research on the QoL of older adults living in slums in developing countries. It is hypothesised that older adults living in slums generally have poor QoL. To improve the lives of slum dwellers, it is necessary to assess their QoL to determine which aspects require improvement. Therefore, this exploratory study aims to provide insight into the QoL of slum-dwelling older adults using the WHO Quality of Life-Brief version (WHOQOL-BREF) questionnaire to assess the QoL of older adults living in two Ghanaian slums. Additionally, associated factors which influence their QoL were explored post-hoc.

\section{METHODS}

\section{Study design and study population}

A community-based, cross-sectional study was conducted between April and May 2020. The population under consideration involved older adults living in two urban slums in the Greater Accra region of Ghana. These slums are in the Ashaiman and Teshie communities. The two slums were adopted for this study due to the comparable literacy rates, despite the prevailing disparities in the type of housing structures and socioeconomic activities. Ashaiman is located close to an industrial city in Ghana and consists of people from different regions and tribes in Ghana. Teshie is mainly a fishing community with majority of the population being indigenous.

Participants were included if they were older adults aged 60 years (retirement age) or older, who have lived in the slums of Ashaiman or Teshie for at least 1 month and could communicate verbally. Critically ill older adults and people with speech impairments who were not able to express themselves verbally were excluded from the study.

\section{Study instrument}

The primary outcome measure of this study is QoL, assessed using the WHOQOL-BREF. ${ }^{31}$ This instrument was chosen based on the results of a scoping review of instruments assessing QoL in African countries. ${ }^{32}$ Detailed information on psychometric properties, related to the use for the slum population, is lacking from previous studies, but the included domains, the feasibility and the length of the instrument, nevertheless, convinced the authors to use the WHOQOL-BREF in this study.

The WHOQOL-BREF consists of four domains. The questions in each domain vary from three to seven. Every question in each domain is rated on a 5-point Likert scale, where 1 represents 'very poor' and 5 represents 'very good'. The first domain is the 'Physical Health' domain. This includes seven questions related to sleep, energy, mobility, extent to which pain prevents performance of necessary tasks, need for medical treatment to function in daily life and level of satisfaction with their work capacity. The second domain is the 'Psychological' domain, with six questions focusing on the ability to concentrate, selfesteem, body image, spirituality and frequency of positive or negative feelings. The third domain covers 'Social relationships' and includes three questions related to satisfaction with personal relationships, social support systems and sexual satisfaction. The fourth is the 'Environmental' domain, which comprises eight questions related to safety and security, satisfaction with one's home and physical environment satisfaction, finances, availability of health and social care availability, access to general information and leisure activities accessibility and satisfaction with transportation.

In addition to the four domains, the WHOQOL-BREF includes two general questions: one about respondents' QoL in general and one related to their satisfaction with health. These questions also have five response options varying from 1 'very poor' to 5 'very good' for rating the QoL and from 1 'very dissatisfied' to 5 'very satisfied' for rating satisfaction with health. Besides using the WHOQOL-BREF, the demographic characteristics of the subjects (gender, age, educational level, religion and marital status) were collected. In addition, data on access to healthcare, current health condition, health services patronised, living arrangements, social support and sources of income were gathered. 


\section{Data collection}

The WHOQOL-BREF questionnaire was used to conduct face-to-face interviews during data collection given difficulties with reading (due to both difficulties in reading and/or poor vision) in the population under consideration. The interviews were done by the first author (PYAA) with four research assistants who were undergraduates of the University of Ghana. The interviewers all have a background in nursing and were trained before the commencement of data collection. During the training, they were introduced to the WHOQOL-BREF and taken through the process of intended data collection. The interviewers needed to be conversant with the questions in two local languages (Twi and Ga). During the face-to-face interviews with subjects, interviewers read the questions out loud and filled in the responses of participants. The original English version of the instrument was translated and administered to participants in the local languages (Ga and Twi). Local language experts translated and back-translated the WHOQOL-BREF questionnaire to ensure that the intended meaning of the original content was intact. Additionally, a pretest of the questionnaire was carried out in a nearby slum and no changes were made afterwards. We used the Strengthening the Reporting of Observational Studies in Epidemiology cross-sectional checklist to write our report. ${ }^{33}$

\section{Sampling method and sample size}

Recruitment took place by involving a key informant in each slum. This key informant was a person working at the municipal assembly of the specific community and visiting the slums very often due to the nature of their work. The key informant used a convenient sampling method to select participants living in the slums. After selecting participants, the snowballing technique was used to increase participation rate. This technique is not new as previous QoL studies involving older adults also used snowballing sampling techniques during sample recruitment. ${ }^{21}{ }^{34}$ The key informant also familiarised the research team with the slum community. Eligible participants were invited and the research team provided studyspecific information personally to the participant. The sample size was calculated to get the number of participants that will be representative of the entire population of older adults in the slums. The sample size is an estimate of how many participants will be needed as a representation of the total sample population. Sample size calculation was done using the Yamane formula. ${ }^{35}$ The two slums under consideration consist of approximately 6000 older inhabitants. Filling in the formula gave an estimated sample size of 375 participants. ${ }^{35}$

Written informed consent, either by signing or thumbprinting (in the case of those who were unable to sign), was required for participation.

\section{Patient and public involvement}

Patients and the public were not involved in the development of the research questions, design and conduct of the study. However, participants were involved in the recruitment of others through the snowball method. The study results will be shared with the participants and other relevant stakeholders through various social media handles and conferences.

\section{Data analysis}

Data were analysed using Statistical Package for Social Sciences (IBM SPSS) V.24.0. Domain scores were scaled in a positive direction (ie, higher scores denote higher QoL). The mean score of items within each domain is used to calculate the domain score. An Excel sheet calculator created by Skvarc $^{36}$ was used to transform the different WHOQOL-BREF domain scores to a 0-100 scale. Cut-off points for QoL in this study were determined based on the literature by Silva and colleagues. ${ }^{37}$ According to Silva and colleagues, ${ }^{37}$ a score $\leq 45$ is considered poor QoL, $46-64$ is considered moderate QoL and any score $>65$ is recorded as high QoL.

In further analyses, the demographic data served as independent variables and the domains of the WHOQOLBREF as dependent variables. Gender and place of residence were depicted as a binominal variable, where ' 1 ' is male/Teshie and ' 2 ' is female/Ashaiman, respectively. All other demographic data were categorical variables. Educational level was categorised into four groups: no formal education, elementary school, high school and above high school. Marital status comprised single, married, divorced and widowed, depicted with numbers. Age was grouped into five categories (60-65, 66-70, 71-75, 76-80, $>81$ ), also depicted with numbers. Finally, place of residence (Teshie or Ashaiman) was documented.

Descriptive analyses were performed to describe the background characteristics as well as the domain scores of the WHOQOL-BREF. To compare the mean distribution of participants' characteristics and their QoL per domain, an independent t-test and analysis of variance (ANOVA) were used. Regression analysis was done to assess the relationship between sociodemographic characteristics and the QoL domains. Analyses of QoL scores in the four domains were performed after transformation to a $0 \%-100 \%$ scale. For the primary hypothesis in this study, the level of significance was set at $p<0.05$. For all other analyses, $\mathrm{p}$ values are reported for generating hypotheses and high false positives were controlled for using multiple comparison adjustments. Nonetheless the results should be interpreted with caution.

\section{RESULTS}

\section{Background characteristics of participants}

In total, 400 people were approached for this exploratory study and they all agreed to participate. This means that a 100\% response rate was achieved. Three subjects were excluded from the analysis as they were below the age of 60 years, resulting in a total sample of 397 respondents.

The background characteristics can be found in online supplemental appendix table 1. Of all participants, 240 
$(60.5 \%)$ were female and the largest age group was 60-65 years $(47.6 \%)$. The majority of the older adults in this population were widowed $(38.5 \%)$, followed by married participants $(31.7 \%)$. In total $44.8 \%$ of the participants had no formal education. When asked about their current illnesses/diseases, $25.2 \%$ had osteoarthritis, followed by $19.2 \%$ with body pain and $17.1 \%$ with high blood pressure. Participants were also asked about their source of income. Most participants $(31.5 \%)$ received their income from their children, $22.9 \%$ were into trading, and $2.0 \%$ were either mechanics, electricians or welders. On the sources of healthcare used, most participants $(39.8 \%)$ patronised pharmacies, with herbal preparations being the least accessed $(4.5 \%)$. When asked about the living arrangements, $33.5 \%$ each either lived alone or with extended family members. Of the total sample population, $17.1 \%$ lived with their children, while $2.5 \%$ lived with others, which include friends and church members. Daughters were the biggest form of social support (28.7\%), followed by siblings of older adults $(17.4 \%)$ and then sons $(16.9 \%)$ (see online supplemental appendix table 2).

The outcomes of the WHOQOL-BREF are described in online supplemental appendix table 3 . When looking at the total population, the perceived overall QoL is neither poor nor good, with participants neither satisfied nor dissatisfied with their health. Transformed QoL scores were rated poor, moderate and high, based on the literature by Silva and colleagues. ${ }^{37}$ According to Silva and colleagues, ${ }^{37}$ the participants in these slums recorded a moderate level of QoL in the psychological (mean 45.7), social (mean 57.0) and environmental (mean 51.6) domains of the WHOQOL-BREF. The physical QoL of the older adults in these slums recorded a mean score of 43.3 .

When looking at the differences between male and female participants, statistically significant differences were found in general QoL $(p<0.001)$, general satisfaction with health $(\mathrm{p}=0.017)$, psychological domain $(p=0.019)$ and environmental domain $(p=0.001)$. In all of these domains, male participants showed a significantly higher QoL compared with their female counterparts.

In the analysis of the various age groups, there were significant differences in the psychological $(\mathrm{p}=0.036)$, physical $(\mathrm{p}=0.003)$ and environmental $(\mathrm{p}=0.003)$ domains.

In online supplemental appendix table 3, it appears that, as age increased, QoL decreased significantly in the physical and environmental domains. Yet, in the psychological domain, those between 76 and 80 years had better psychological QoL compared with those aged 66-70 years.

For marital status, significant differences in the various domains were seen in the perceived QoL $(p<0.001)$, psychological $(p<0.001)$, social $(p<0.001)$ and environmental $(\mathrm{p}=0.001)$ domains. Participants who are married had the highest scores in these domains, followed by participants who are divorced, widowed and single.

In an examination of differences in QoL among the various educational levels, there were significant differences in all domains, except for the social domain. In general, QoL was significantly higher among participants with higher educational status. Lastly, when looking at the difference in QoL between place of residence, older adults in the Ashaiman slum showed a statistically significant difference in perceived QoL $(\mathrm{p}<0.001)$, psychological QoL $(p=0.004)$ and environmental QoL $(p<0.001)$.

In a one-way ANOVA of the mean differences in QoL of participants with different sources of income, there was a statistical significance in the satisfaction with health domain only. Participants who received pensions had higher means in most domains (overall QoL, satisfaction with health, physical QoL), followed by participants who had financial support from family/siblings (higher scores on the environmental and psychological domains). Participants who received financial support from friends had the highest QoL score in the social QoL domain.

An ANOVA comparing mean QoL scores of participants with different sources of social support showed no statistical differences in scores between different sources of social support (see online supplemental appendix table 2). An ANOVA comparing the living arrangements of participants showed that people who lived with extended family had high environmental QoL scores, overall QoL scores and satisfaction with health scores. Those who lived with their children had high psychological QoL scores.

An ANOVA for regression analysis of QoL scores and demographic characteristics was done to show if certain domains are influencing QoL to a higher extent than other domains (see online supplemental appendix table $4)$. Variances between the various domains showed that the environmental domain had the highest influence at $46.2 \%$, followed by the psychological domain (43.7\%), the physical domain (31\%) and the social domain (20.4\%). When looking at the variances between domains, calculated with the adjusted $r^{2}$, for women at a significance of $\mathrm{p}<0.001$, the environmental domain had the greatest influence $(36.3 \%$ variance in $\mathrm{QoL})$, followed by the psychological domain $(30.8 \%)$, the physical domain $(26.0 \%)$ and the social domain (12.9\% variance in QoL). Among men at a significance of $\mathrm{p}<0.001$, the psychological domain had a $59.3 \%$ influence on total QoL, followed by the environmental domain (58.3\%), the physical domain $(37.3 \%)$ and the social domain $(33.2 \%)$.

For older adults in the 60-65 years age category, environmental QoL had the highest influence (adjusted $\mathrm{r}^{2}=0.488$ ) on their QoL at a significance of $\mathrm{p}<0.001$, followed by psychological QoL (adjusted $r^{2}=0.469$ ) and then physical QoL (adjusted $r^{2}=0.279$ ), and lastly social QoL (adjusted $\left.r^{2}=0.210\right)$. Environmental QoL has a greater influence on the general QoL of older adults between 60 and 75 years and psychological QoL has a greater influence on the QoL of participants aged $>76$ years (see online supplemental appendix table 4). The QoL of participants with no formal education was likely to be influenced $45.7 \%$ by environmental QoL (adjusted $r^{2}=0.457$ ), while those who attained an education of above high school had their QoL being impacted $54.4 \%$ by psychological QoL (adjusted $r^{2}=0.544$ ). Environmental QoL had a $33.9 \%$ influence on the QoL of participants living in slums in 
the Teshie community (adjusted $\mathrm{r}^{2}=0.339$ ), while the QoL of participants in Ashaiman was influenced $72.3 \%$ by the psychological QoL (adjusted $r^{2}=0.723$ ). The results from other subgroup analyses on variance can be found in online supplemental appendix table 4 .

\section{DISCUSSION}

This study aimed to assess the QoL of older adults living in two Ghanaian slums using the WHOQOL-BREF questionnaire. It was hypothesised that older adults living in slums generally have poor QoL. Overall, there is an indication that older adults living in slums have poor to moderate QoL indeed. As previously indicated, this study is exploratory and additional hypotheses were generated post-hoc. The first is that the physical QoL of older adults in slums is poor. Second, men have higher mean scores on all domains than women. Third, educational level and marital status influence the QoL of older adults in most domains. Additionally, receiving financial support positively impacts QoL. Also, the population recorded an average rating of neither poor nor good in the overall QoL question and were neither satisfied nor dissatisfied in the health satisfaction question. Finally, the results of a comparison of the two slums underscore the need to pay particular attention to the environmental QoL of older adults in the Teshie slum and the psychological QoL domain of those in the Ashaiman slum.

Overall, there is an indication that older adults living in slums have a moderate QoL in the environmental QoL domain. The results underscore the need to pay particular attention to the environmental QoL of older adults in the Teshie slum and the psychological QoL domain of those in the Ashaiman slum to improve the QoL in total. Overall, there is an indication that older adults living in slums have poor physical QoL. On average, a moderate QoL level was observed in the environmental QoL domain of older adults in the slums. This is remarkable because, in slums, one would have expected a very poor QoL in the environmental domain due to confirmed $^{38-40}$ well-known characteristics of slums such as the lack of safety and security, poor quality of housing, overcrowding, and unavailability of health and social care. An explanation of this finding could be that most older adults might have adapted to their environment and tried to make the best of what is at their disposal. Another explanation could be that slum amenities and living conditions are not much worse than the prior living arrangements (rural life) of these older adults.

In the current study, women constituted the majority $(61 \%)$ of the population, similar to the study by Akosile et $a l^{26}$ This was expected as women are estimated to live longer than their male counterparts ${ }^{41}{ }^{42}$ even in underdeveloped countries. Additionally, the age of this study population ranged between 60 and 98 years, with a mean age of 68.89. Similar to most studies carried out in Africa among older adults, the age of most participants was between 60 and 69 years. ${ }^{43}$ This is indicative of an increasing life expectancy and the need to promote interest in older adults. Participants in this study mostly had no formal education and this is consistent with studies conducted in slums from various countries like India, ${ }^{44}$ Iran, ${ }^{45}$ Bangladesh $^{46}$ and sub-Saharan Africa. ${ }^{43} 47-49$

Low QoL scores were observed for all participants in the physical and psychological domains. This result affirms the study by Alaazi and colleagues ${ }^{21}$ comparing slum and nonslum dwellers, where participants had low QoL mean scores in both psychological and physical health domains. Poor health conditions and increased dependency, as well as low self-esteem and frequency of negative feelings, as postulated by Pathak $e t a l^{50}$ could account for the low scores. Although older adults may receive social support from their family members, older adults might feel more comfortable if this support is from their children. This may also account for low scores in the psychological QoL domain of those living with their extended family compared with high psychological scores of those living with their children.

Men recorded higher means than women in all domains of the WHOQOL-BREF. This is similar to the findings by Van Nguyen and colleagues, ${ }^{51}$ who suggested comparable cultural, economic and environmental contexts could yield a similar outcome. The psychological and environmental domains had statistically significant differences for gender on QoL, where men showed higher QoL compared with women. In the psychological domain, men in the slum have better self-esteem and often have positive feelings as they try to make ends meet in their current settlement. The gender differences could be attributed to the roles men and women play in the Ghanaian society. Anecdotal evidence suggests that men show dominance and supremacy in Ghanaian culture. Additionally, most men in the slums first migrated from the village and brought their spouses to live with them after settling in the slums. ${ }^{5253}$ In the environmental domain, men who often leave the slums to work are more financially sound and have access to general information compared with women. Moreover, as breadwinners, Ghanaian men usually put up the expression of 'all is well' even when it is not and therefore do not easily admit failure compared with women. In addition, when it comes to issues of safety and money, women are often dependent on their husbands. For women, the lowest mean score was shown in the psychological health domain (mean=41.95), implying negative feelings, low self-esteem, and low body image and appearance. Women living in slum communities might feel they have not achieved much and feel demeaned because of the stigma of living in slums ${ }^{54}$ and societal upbringing. ${ }^{55}$ This is consistent with the findings of Alaazi and colleagues. ${ }^{21}$

The highest overall QoL score was found for the social relationship domain (mean $=57.77$ ), an indication of relative satisfaction of both men and women with personal relationships and support received. This may be attributed to the potential role of the Ghanaian extended family system, in which children offer support to their older family members even in the slum. Children were the highest sources of income for the older adults in this study. Nonetheless, older adults in this study who received pensions were most satisfied with their health. 
This could be attributed to the ability of such individuals to access and afford healthcare when ill as their previous employers will usually refund hospital bills.

The QoL of participants generally decreased with age, similar to previous studies. ${ }^{812656-58}$ This could be attributed to the gradual degeneration and weakness of the human body as individuals age. Medically diagnosed osteoarthritis was the prevalent condition among the study population. Considering the uneven walkways in the slums, the degeneration of joint cartilage and the underlying bone cause pain especially in the hip and knee, making older adults more dependent on others. Participants between 76 and 80 years had a better psychological QoL compared with those aged 66-70 years, implying they had better self-esteem, body image, spirituality and frequency of positive or negative feelings, similar to a study by Charles and Kulandai ${ }^{59}$ Spirituality in the Ghanaian culture is very prevalent most especially among older adults as they draw closer to their Maker. This could account partly for this result as older adults at this stage feel they are ready to exit the world accepting their previous life, and may not have considerable doubts in their lives. ${ }^{616214748}$

With the sociodemographic characteristics of the current study population, both marital status and educational level of participants had a significant effect on the QoL of participants. Married participants had higher means in all domains compared with all the other categories, especially the single participants. This confirms findings of studies by Lee $e t a l^{60}$ and Yaya $e t a l .{ }^{57}$ Except for the physical health domain, higher educational level could be equated to better QoL in the other domains, similar to the findings by Ejiakor et al. ${ }^{61}$

Comparing the two slums, older adults in Ashaiman showed better QoL in the perceived overall QoL and the psychological and environmental domains. This could be attributed to the proximity of Ashaiman to the industrial city and therefore inhabitants could more easily get access to the resources the non-slum dwellers in the industrial city enjoy. Additionally, caregivers of these older adults engage more frequently in various economic activities compared with the restricted/narrower options (fishing, fish mongering and small-scale trading) of those in Teshie. However, there were no significant differences in the physical and social relationship domains between the participants of both slums.

\section{Strengths and limitations}

A strength of this study is that this is the first study to assess the QoL of older adults in two different slum communities in Ghana.

There was a $100 \%$ response rate and there were no missing data, which contribute to the methodological strength of the study. The $100 \%$ response rate can be attributed to the fact that all participants were approached personally and the presence of the first author and research assistants which encouraged respondents. Additionally, breakfast packages given to participants after completing the questionnaires could have contributed to the $100 \%$ response rate. However, what could have biased our results is the fact that a convenient sampling technique was used to select participants, instead of a probability sampling method. The reason for this is the nature of the slum set-up and the frail population involved. It was not possible to apply a probability sampling method among the older adults living in the slums and therefore convenience sampling was used. Additionally, the background characteristics of other studies focused on older adults in slum settings ${ }^{2151}$ are comparable with our findings, which makes it likely that our convenience sampling method did not affect the generalisability of our results.

Another limitation could be ascribed to the crowded nature of the slum setting: there was no privacy during data collection and other slum dwellers were often listening to the interviews. This could have influenced the answers given by the participants. Lastly, even though the WHOQOL-BREF questionnaire has been validated in various languages, this is not the case for the languages used in this study. We did perform a translation-back translation procedure and the instrument was pretested in a neighbouring slum; we therefore expect that this did not influence our results to a large extent.

\section{Implications for practice and research}

In all domains of the WHOQOL-BREF, women have lower QoL than men. Therefore, we advise governmental and non-governmental agencies to focus on helping women in slums achieve better self-esteem and increase the frequency of positive feelings. An important way to achieve this is generally through education. Poor scores in physical QoL among study participants were also observed. Further research is needed to determine what could account for the moderate QoL recorded in this slum setting, and additionally to assess which factors could contribute to the poor physical QoL of old people in slums. Policymakers on health are also encouraged to incorporate structures to assist community health workers to strategise home visits to these older adults. Establishment of community facilities well equipped to meet the QoL in totality is also recommended. The findings of this study can assist in policy development to include strategies to further improve the QoL of older adults in slums.

\section{CONCLUSION}

The findings of this study show that older adults living in slums in Ghana had moderate psychological, social and environmental QoL and poor physical QoL. Therefore, health policy development must consider the specific needs of older adults in slums and direct policies to meet these needs to further improve their overall QoL.

\section{Author affiliations}

${ }^{1}$ Community Health Nursing Department, School of Nursing and Midwivery, University of Ghana, Legon, Ghana

${ }^{2}$ Faculty of Health Medicine and Life Sciences, Department of Health Services Research, Maastricht University, Maastricht, The Netherlands 
${ }^{3}$ Public Administration and Health Services Management, University of Ghana, Legon, Ghana

${ }^{4}$ Department of Nursing Science, Medical University of Graz, Graz, Austria ${ }^{5}$ Department of General Practice, School for Public Health and Primary Care (CAPHRI), Faculty of Health Medicine and Life Sciences, Maastricht University, Maastricht, The Netherlands

Acknowledgements The authors are grateful to all data collectors, especially Harriet Adu Gyamfi for spearheading the process.

Contributors PYAA, IE, CL and JMGAS conceptualised the study. PYAA collected the data. PYAA, IE and AAA analysed the data. All authors reviewed the literature and read through the final manuscript before submission. PYAA nd JMGAS are guarantors for the conduct of this study

Funding The authors have not declared a specific grant for this research from any funding agency in the public, commercial or not-for-profit sectors.

Competing interests None declared.

Patient consent for publication Consent was obtained from patient(s).

Ethics approval This study involves human participants and was approved by the Institutional Review Board of 37 Military Hospital (37MH-IRB IPN 199/2018). Permission to perform this study in Ashaiman and Teshie was provided by the municipal assemblies of the selected slums. Participants gave informed consent to participate in the study before taking part.

Provenance and peer review Not commissioned; externally peer reviewed.

Data availability statement Data are available upon reasonable request.

Supplemental material This content has been supplied by the author(s). It has not been vetted by BMJ Publishing Group Limited (BMJ) and may not have been peer-reviewed. Any opinions or recommendations discussed are solely those of the author(s) and are not endorsed by BMJ. BMJ disclaims all liability and responsibility arising from any reliance placed on the content. Where the content includes any translated material, BMJ does not warrant the accuracy and reliability of the translations (including but not limited to local regulations, clinical guidelines, terminology, drug names and drug dosages), and is not responsible for any error and/or omissions arising from translation and adaptation or otherwise.

Open access This is an open access article distributed in accordance with the Creative Commons Attribution Non Commercial (CC BY-NC 4.0) license, which permits others to distribute, remix, adapt, build upon this work non-commercially, and license their derivative works on different terms, provided the original work is properly cited, appropriate credit is given, any changes made indicated, and the use is non-commercial. See: http://creativecommons.org/licenses/by-nc/4.0/.

ORCID iDs

Priscilla Yeye Adumoah Attafuah http://orcid.org/0000-0002-6736-0348

Aaron Asibi Abuosi http://orcid.org/0000-0003-2226-4309

\section{REFERENCES}

1 Population Reference Bureau. Average life expectancy at birth in 2020, by continent and gender (in years), 2020. Available: https:// www.statista.com/statistics/270861/life-expectancy-by-continent/

2 Agustina R, Dartanto T, Sitompul R, et al. Universal health coverage in Indonesia: concept, progress, and challenges. Lancet 2019;393:75-102.

3 Khan HTA, Hussein S, Deane J. Nexus between demographic change and elderly care need in the Gulf cooperation Council (GCC) countries: some policy implications. Ageing Int 2017;42:466-87.

4 Singh GK, Daus GP, Allender M, et al. Social determinants of health in the United States: addressing major health inequality trends for the nation, 1935-2016. Int J MCH AIDS 2017;6:139.

5 Arslantaș H, Adana F, Abacigil Ergin F, et al. Loneliness in elderly people, associated factors and its correlation with quality of life: a field study from Western turkey. Iran J Public Health 2015;44:43.

6 James AC, Crewdson JA. The effect of loneliness in the elderly population: a review. Healthy Aging Clin Care Elder 2016;8:1-8.

7 Liu L, Gou Z, Zuo J. Social support mediates loneliness and depression in elderly people. J Health Psychol 2016;21:750-8.

8 Joshi MR, Chalise HN, Khatiwada PP. Quality of life of Nepalese elderly living in rural Nepal. J Gerontol Geriatr 2018;7:484.

9 Tripathi RK. Quality of life: an important issue in geriatric research. J Gerontol Geriatr Res 2012;1:1-12.
10 World Health Organization. Division of mental health and prevention of substance abuse. (1997). WHOQOL: measuring quality of life. World Health organization. Available: https://apps.who.int/iris/handle/ 10665/63482

11 Brett CE, Dykiert D, Starr JM, et al. Predicting change in quality of life from age 79 to 90 in the Lothian birth cohort 1921. Qual Life Res 2019;28:737-49.

12 Haider S, Luger E, Kapan A, et al. Associations between daily physical activity, handgrip strength, muscle mass, physical performance and quality of life in prefrail and frail communitydwelling older adults. Qual Life Res 2016;25:3129-38.

13 Ghosh S, Bandyopadhyay S, Bhattacharya S, et al. Quality of life of older people in an urban slum of India. Psychogeriatrics 2014;14:241-6.

14 Singh BN. Socio-economic conditions of slums dwellers: a theoretical study. KAAV Int J 2016;3:5-20.

15 Sufaira.C SC. Socio economic conditions of urban slum dwellers in Kannur Municipality. IOSR-JHSS 2013;10:12-24.

16 Mberu B, Béguy D, Ezeh AC. Internal migration, urbanization and slums in sub-Saharan Africa. In: Africa's population: In search of a demographic dividend. Springer, Cham, 2017: 315-32.

17 Lucci P, Bhatkal T, Khan A. What works in improving the living conditions of slum dwellers. ODI Dimenstion Paper 2015;4.

18 Gómez-Olivé FX, Thorogood M, Clark B, et al. Self-reported health and health care use in an ageing population in the Agincourt subdistrict of rural South Africa. Glob Health Action 2013;6:181-92.

19 Deshmukh S, Kalaskar SK, Kadam SB, et al. Utilization pattern of health services for non-communicable diseases in an urban slum: a study of Turbhe stores slum in Navi Mumbai, Maharashtra, India. Int J Community Med Public Health 2016;4:139.

20 Aboderin I, Kano M, Owii HA. Toward "age-friendly slums"? Health challenges of older slum dwellers in Nairobi and the applicability of the age-friendly city approach. Int J Environ Res Public Health 2017;14:1259.

21 Alaazi DA, Menon D, Stafinski T, et al. Quality of life of older adults in two contrasting neighbourhoods in Accra, Ghana. Soc Sci Med 2021;270:113659.

22 Corburn J, Vlahov D, Mberu B, et al. Slum health: arresting COVID-19 and improving well-being in urban informal settlements. J Urban Health 2020;97:348-57.

23 World Health Organization. Global strategy and action plan on ageing and health. Geneva: World Health Organization, 2017.

24 Kangmennaang J, Bisung E, Elliott SJ. 'We are drinking diseases': Perception of water insecurity and emotional distress in urban slums in Accra, Ghana. Int J Environ Res Public Health 2020;17:890.

25 Price HD, Adams EA, Nkwanda PD, et al. Daily changes in household water access and quality in urban slums undermine global safe water monitoring programmes. Int J Hyg Environ Health 2021;231:113632.

26 Akosile CO, Mgbeojedo UG, Maruf FA, et al. Depression, functional disability and quality of life among Nigerian older adults: prevalences and relationships. Arch Gerontol Geriatr 2018;74:39-43.

$27 \mathrm{Ko} \mathrm{H}$, Park Y-H, Cho B, et al. Gender differences in health status, quality of life, and community service needs of older adults living alone. Arch Gerontol Geriatr 2019;83:239-45.

28 Millar BM, Starks TJ, Gurung S, et al. The impact of comorbidities, depression, and substance use problems on quality of life among older adults living with HIV. AIDS Behav 2017;21:1684-90.

29 Hyams AV, Hay-McCutcheon M, Scogin F. Hearing and quality of life in older adults. J Clin Psychol 2018;74:1874-83.

30 Lima S, Teixeira L, Esteves R, et al. Spirituality and quality of life in older adults: a path analysis model. BMC Geriatr 2020;20:1-8.

31 Skevington SM, Lotfy M, O'Connell KA, et al. The world Health organization's WHOQOL-BREF quality of life assessment: psychometric properties and results of the International field trial. A report from the WHOQOL group. Qual Life Res 2004;13:299-310.

32 Attafuah PY, Everink IH, Halfens RJ, et al. Instruments used to assess quality of life of older adults in African countries: a scoping review. BMC Geriatr 2021;21:1-11.

33 von Elm E, Altman DG, Egger M, et al. The strengthening the reporting of observational studies in epidemiology (STROBE) statement: guidelines for reporting observational studies. Int J Surg 2014;12:1495-9.

34 Arianmehr T, Cheraghi Z, Ahmadpanah M, et al. Quality of life and the related factors in Iranian transgender people: a cross-sectional study. Journal of Public Health 2021:1-7.

35 Yamane T. Elementary sampling theory. New Jersey: Prentice-Hall, Inc, 1967.

36 Skvarc D. Re: how do I calculate total score for WHOQOL-BREF? 2018. Available: https://www.researchgate.net/post/How_do_I calculate_total_score_for_WHOQOL-BREF/5aa5cc6c40485460 3d126f05/citation/download 
37 Silva PAB, Soares SM, Santos JFG, et al. Cut-off point for WHOQOLbref as a measure of quality of life of older adults. Rev Saude Publica 2014;48:390-7.

38 Zerbo A, Delgado RC, González PA. Vulnerability and everyday health risks of urban informal settlements in sub-Saharan Africa. Glob Health J 2020;4:46-50.

39 Arize I, Ogbuabor D, Mbachu C, et al. Stakeholders' Perspectives on the Unmet Needs and Health Priorities of the Urban Poor in South-East Nigeria. Int Q Community Health Educ 2021;19:272684X211033441.

40 Moita S, Tuwu D, Darmawan A. Strategy for prevention and quality improvement of urban Slumps based on community Empowerment. IJSEI 2021;2:98-109.

41 Owusu M, Nursey-Bray M, Rudd D. Gendered perception and vulnerability to climate change in urban slum communities in Accra, Ghana. Reg Environ Change 2019;19:13-25.

42 Lamptey I, Boateng A, Hamenoo E. Exploring the experiences of elderly persons cared for by family caregivers in Ghana. Int $j$ innov res adv stud 2018;5:199-208.

43 Barua K, Borah M, Deka C, et al. Morbidity pattern and healthseeking behavior of elderly in urban slums: a cross-sectional study in Assam, India. J Family Med Prim Care 2017;6:345.

44 Panda M, Pathak R, Islam F, et al. Interplay of multimorbidity and polypharmacy on a community dwelling frail elderly cohort in the peri-urban slums of Delhi, India. J Family Med Prim Care 2020;9:1647.

45 Amiresmaili M, Yazdi-Feyzabadi V, Heidarijamebozorgi M. Health services utilization among slum dwellers: an experience from Iran. $J$ Educ Health Promot 2019;8:210.

46 Sutradhar I, Gayen P, Hasan M, et al. Eye diseases: the neglected health condition among urban slum population of Dhaka, Bangladesh. BMC Ophthalmol 2019;19:1-8.

47 Mohamed SF, Haregu TN, Uthman OA, et al. Multimorbidity from chronic conditions among adults in urban slums: the AWI-Gen Nairobi site study findings. Glob Heart 2021;16:6.

48 Chepngeno-Langat G, van der Wielen N, Evandrou M, et al. Unravelling the wider benefits of social pensions: secondary beneficiaries of the older persons cash transfer program in the slums of Nairobi. J Aging Stud 2019;51:100818.

49 Aboderin I, Nanyonjo A. Musculoskeletal health conditions among older populations in urban slums in sub-Saharan Africa. Best Pract Res Clin Rheumatol 2017;31:115-28.
50 Pathak BG, Deshpande S, Manapurath RM. Magnitude and genderspecific circumstances of depression among elderly population residing in an urban slum area of a City in Maharashtra: a mixedmethod study. Indian J Public Health 2020;64:405.

51 Van Nguyen T, Van Nguyen H, Duc Nguyen T, et al. Difference in quality of life and associated factors among the elderly in rural Vietnam. J Prev Med Hyg 2017;58:E63-71.

52 Darkwah AK, Thorsen D, Boateng DA. Good for parents but bad for wives: migration as a contested model of success in contemporary Ghana, 2019.

53 Dery I. "To be a man is not easy": Everyday economic marginality and configurations of masculinity among rural Ghanaian youth. Mcs 2019;8:171-94.

54 Halliday E, Brennan L, Bambra C, et al. 'It is surprising how much nonsense you hear': how residents experience and react to living in a stigmatised place. A narrative synthesis of the qualitative evidence. Health Place 2021;68:102525.

55 Aziato L, Iddrisu M, Attafuah PY. African Women in Academia Breaking the Glass Ceiling: Towards Attainment of the Sustainable Development Goals. In: Empowering African women for sustainable development. Palgrave Macmillan, Cham, 2020: 107-19.

56 Risal A, Manandhar S, Manandhar K, et al. Quality of life and its predictors among aging people in urban and rural Nepal. Qual Life Res 2020;29:3201-12.

57 Yaya S, Idriss-Wheeler D, Sanogo N'doh Ashken, Vezina M, et al. Self-reported activities of daily living, health and quality of life among older adults in South Africa and Uganda: a cross sectional study. BMC Geriatr 2020;20:1-11.

58 Ralston M. The role of older persons' environment in aging well: quality of life, illness, and community context in South Africa. Gerontologist 2018;58:111-20.

59 Charles S, Kulandai A. Psychological well being and quality of life of pensioners. Studies in Indian place names. UGC Care Journal $2020 ; 40$.

60 Lee KH, Xu H, Wu B. Gender differences in quality of life among community-dwelling older adults in low- and middle-income countries: results from the study on global ageing and adult health (SAGE). BMC Public Health 2020;20:114.

61 Ejiakor I, Achigbu E, Onyia O, et al. Impact of visual impairment and blindness on quality of life of patients in Owerri, IMO state, Nigeria. Middle East Afr J Ophthalmol 2019;26:127. 